\title{
AN EXPERIMENT IN INTERCROPPING CUCUMBERS AND TOMATOES IN SOUTHERN MICHIGAN, U.S.A.
}

\author{
BRIAN SCHULTZ ${ }^{1}$, CRUZ PHILLIPS, PETER ROSSET and JOHN VANDERMEER \\ Division of Biological Sciences, University of Michigan, Ann Arbor, Michigan 48109 \\ (U.S.A.) \\ (Accepted for publication 26 November 1981)
}

\section{ABSTRACT}

Schultz, B., Phillips, C., Rosset, P. and Vandermeer, J., 1982. An experiment in intercropping cucumbers and tomatoes in southern Michigan, U.S.A. Scientia Hortic., 18:

$1-8$.

Yields are reported for an experimental intercrop of tomatoes and cucumbers in southeastern Michigan, U.S.A., during the 1980 growing-season. The land equivalent ratio $(L E R)$ was 1.14 , that is, $14 \%$ more land would be needed to produce the same yield from two monocultures as from a unit area of intercrop. The intercrop advantage was statistically significant. The potential impact of prices, variation in cucumber grades harvested, and risk avoidance by producers are briefly discussed.

\section{INTRODUCTION}

A review of intercropping studies reveals that the two most common processing vegetable crops in the mid-western United States, tomatoes and cucumbers, have never been investigated with respect to their potential as an intercrop (Trenbath, 1974; ASA, 1976; Kass, 1978; Willey, 1979). Our study is a first attempt at elucidating the biological and economic aspects of intercropping these two common vegetables.

We follow standard procedure in assessing yield advantage. If $P_{\mathrm{c}}$ is production of cucumbers in polyculture, $P_{\mathrm{t}}$ is production of tomatoes in polyculture, $M_{\mathrm{c}}$ is production of cucumbers in monoculture, and $M_{\mathrm{t}}$ is production of tomatoes in monoculture, we define relative yield total as

$R Y T=P_{\mathrm{c}} / M_{\mathrm{c}}+P_{\mathrm{t}} / M_{\mathrm{t}}=R Y_{\mathrm{c}}+R Y_{\mathrm{t}}$

$R Y T$ can also be expressed more intuitively as the land equivalent ratio ( $L E R$ ), or the amount of land one would need to produce in monocultures exactly as much of each crop as could be produced on one hectare of polyculture. The intercrop over-yields biologically if $R Y T>1$.

${ }^{1}$ Author to whom correspondence should be addressed. 
An alternative assessment procedure recognizes the importance of the economic value of the crops, and defines an advantage for the intercrop only if the dollar value of the polyculture is greater than the dollar value of the highest yield in monoculture. We define the relative value total as $R V T=\left(P_{\mathrm{c}}+P_{\mathrm{t}}\right) / M_{\mathrm{c}}$

where the yields are expressed in dollar values. The intercrop then overyields economically if $R V T>1$.

Stability in yields is another important potential advantage of intercropping (e.g. Rao and Willey, 1980b; Norman, 1974). It is most commonly assessed by the coefficient of variation $(C V=s / \bar{x})$ over time or space, but reducing the risk of extremely bad years and predictability are also important.

\section{MATERIALS AND METHODS}

The study was done at the University of Michigan Matthaei Botanical Gardens. The Gardens are located on a 100-ha site astride Fleming Creek, $5 \mathrm{~km}$ north of its entry into the Huron River. The area includes sandy glacial till and gravelly kame soils on the rolling uplands, and sandy or silty soils on the flood-plains and terraces. The study site was $120 \mathrm{~m} \times 80 \mathrm{~m}$, located on upland sandy soils. It had been uncultivated, but mowed annually, for at least 10 years.

The experiment consisted of 3 treatments: tomato monoculture, cucumber monoculture, and tomato-cucumber polyculture. A randomized block design was used. Sixteen blocks, each with 3 randomly positioned treatment plots, were arranged in pairs along a north-south gradient. Plots were $7 \mathrm{~m} \times 7 \mathrm{~m}$ with a $1-\mathrm{m}$ border. Yield data were taken by neglecting $1 \mathrm{~m}$ of edge in each plot, and by picking from two sub-plots of $2.5 \mathrm{~m} \times 2.5 \mathrm{~m}$ each.

We planted on 30 and 31 May 1980. Tomato seedlings ('Heinz 1350') were transplanted and cucumbers ('Northrup-King Straight Eight') were directseeded. Rows were spaced $1 \mathrm{~m}$ apart for monocultures and intercrops. Within rows, tomatoes were spaced $1 \mathrm{~m}$ apart, cucumbers $0.33 \mathrm{~m}$. Densities were as recommended for maximum yields of monocultures. The polycultures consisted of both crops in the same rows and at their monocultural densities. Fertilizer (6-24-24) was applied in bands (approximately $0.5 \mathrm{~m}$ wide) and hoed in by hand just before planting, at the application rate of $1000 \mathrm{lbs} / \mathrm{acre}$. Four harvests were done, in September and early October.

\section{RESULTS}

The yields from both sub-plots and all harvests were combined, and are given in Table I. Within each block there is a clear reduction in yield for both crop types when intercropped.

While the weight of tomatoes is a consistent and accurate representation 
of meaningful yield, the weight of cucumbers is not. Many cucumbers were harvested beyond meaningful grade levels, and in any economic analysis it is necessary to consider the distribution of grades. It thus seems more appropriate to use the number of cucumbers in computing relative yields (cf. Ells and McSay, 1981). This enables the computation of the consequences of different grade-distributions later.

The results, using weights of tomatoes and numbers of cucumbers, showed over yielding, with an average $R Y T$ of 1.14 (Table II).

The relative yields are plotted in Fig. 1, along with the critical $R Y T=1$

\section{TABLE I}

Yields of tomatoes and cucumbers by block in monoculture and intercrop

\begin{tabular}{|c|c|c|c|c|c|}
\hline \multirow[t]{2}{*}{ Block } & \multirow[t]{2}{*}{ Treatment } & \multicolumn{2}{|l|}{ Tomato } & \multicolumn{2}{|c|}{ Cucumber } \\
\hline & & $\begin{array}{l}\text { Weight } \\
(\mathrm{kg})\end{array}$ & Number & $\begin{array}{l}\text { Weight } \\
(\mathrm{kg})\end{array}$ & Number \\
\hline \multirow[t]{2}{*}{ I } & Monoculture & 46 & 411 & 147 & 274 \\
\hline & Intercrop & 43 & 379 & 63 & 122 \\
\hline \multirow[t]{2}{*}{ II } & Mono & 82 & 671 & 134 & 256 \\
\hline & Inter & 43 & 342 & 52 & 104 \\
\hline \multirow[t]{2}{*}{ III } & Mono & 66 & 545 & 107 & 200 \\
\hline & Inter & 37 & 285 & 70 & 155 \\
\hline \multirow[t]{2}{*}{ IV } & Mono & 53 & 356 & 151 & 240 \\
\hline & Inter & 32 & 151 & 70 & 144 \\
\hline \multirow[t]{2}{*}{ V } & Mono & 67 & 561 & 174 & 320 \\
\hline & Inter & 32 & 276 & 46 & 97 \\
\hline \multirow[t]{2}{*}{ VI } & Mono & 70 & 556 & 158 & 271 \\
\hline & Inter & 40 & 367 & 49 & 96 \\
\hline \multirow[t]{2}{*}{ VII } & Mono & 56 & 399 & 128 & 248 \\
\hline & Inter & 42 & 362 & 78 & 159 \\
\hline \multirow[t]{2}{*}{ VIII } & Mono & 59 & 471 & 118 & 221 \\
\hline & Inter & 46 & 426 & 43 & 98 \\
\hline \multirow[t]{2}{*}{ IX } & Mono & 60 & 521 & 132 & 225 \\
\hline & Inter & 47 & 426 & 54 & 102 \\
\hline \multirow[t]{2}{*}{$\mathrm{X}$} & Mono & 69 & 589 & 177 & 327 \\
\hline & Inter & 39 & 330 & 66 & 153 \\
\hline \multirow[t]{2}{*}{ XI } & Mono & 59 & 471 & 123 & 229 \\
\hline & Inter & 27 & 240 & 62 & 122 \\
\hline \multirow[t]{2}{*}{ XII } & Mono & 45 & 371 & 188 & 300 \\
\hline & Inter & 39 & 281 & 68 & 146 \\
\hline \multirow[t]{2}{*}{ XIII } & Mono & 64 & 555 & 132 & 221 \\
\hline & Inter & 30 & 303 & 75 & 159 \\
\hline \multirow[t]{2}{*}{ XIV } & Mono & 54 & 463 & 172 & 280 \\
\hline & Inter & 38 & 332 & 44 & 90 \\
\hline \multirow[t]{2}{*}{ XV } & Mono & 60 & 657 & 150 & 266 \\
\hline & Inter & 44 & 382 & 74 & 123 \\
\hline \multirow[t]{2}{*}{ XVI } & Mono & 62 & 621 & 104 & 195 \\
\hline & Inter & 35 & 339 & 39 & 86 \\
\hline
\end{tabular}


TABLE II

Relative yields and relative yield totals (based on mean monoculture yield)

\begin{tabular}{llll}
\hline Block & $R Y_{\text {tom }}$ & $R Y_{\text {cuc }}$ & $R Y T$ \\
\hline I & 0.702 & 0.480 & 1.182 \\
II & 0.709 & 0.409 & 1.118 \\
III & 0.604 & 0.610 & 1.214 \\
IV & 0.530 & 0.567 & 1.097 \\
V & 0.522 & 0.382 & 0.904 \\
VI & 0.664 & 0.378 & 1.042 \\
VII & 0.694 & 0.626 & 1.320 \\
VIII & 0.754 & 0.386 & 1.140 \\
IX & 0.776 & 0.402 & 1.178 \\
X & 0.634 & 0.602 & 1.236 \\
XI & 0.440 & 0.480 & 0.920 \\
XII & 0.634 & 0.575 & 1.209 \\
XIII & 0.493 & 0.626 & 1.119 \\
XIV & 0.619 & 0.354 & 0.973 \\
XV & 0.724 & 0.484 & 1.209 \\
XVI & 0.582 & 0.339 & 0.921 \\
& & & \\
Mean & & & 1.111 \\
\hline
\end{tabular}

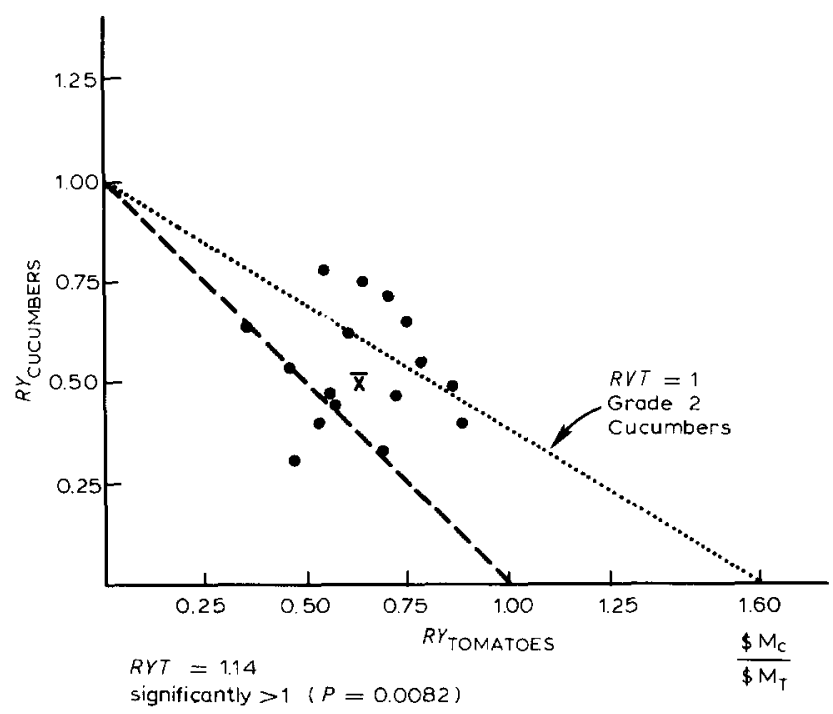

Fig. 1. Relative yields for cucumbers and tomatoes for all 16 plots. Also indicated are criteria for biological overyielding $(R Y T>1)$ and economic overyielding $(R V T>1)$.

line. Overyielding occurred in 12 of the 16 blocks. The use of parametric tests of significance for $R Y T$ 's has been questioned (Fisher, 1979). In order better to approximate normality, we used the overall mean monocultural yields (constants) in the denominators to figure $R Y T$ 's for the $t$-test. This 
approach shows overyielding in this experiment to be significant ( $p=0.0030$ ). Rao and Willey (1980a) argue that the larger-than-normal standard errors of $R Y T$ distributions makes parametric tests conservative; a $t$-test on standard $R Y T$ 's by block from our data also indicates significance ( $p=0.0082)$.

In terms of dollar values, polyculture return should also be compared with that of the most valuable monoculture. Further, the grade of the cucumbers obtained affects the values realized. Prices (Table III) for 4 grades of cucumbers were those used by O'Sullivan and Colwell (1980). The highest dollar value suggested by our data would be obtained from a monoculture of Grade 2 cucumbers $(\$ 5565 / \mathrm{ha})$. The higher value per $\mathrm{kg}$ of smaller, Grade 1 cucumbers is more than offset by the greater absolute weight of the Grade 2 cucumbers. Assuming this admittedly impossible grade distribution (all Grade 2) for the sake of argument, we can plot the critical line for $R V T=$ 1 on the $R Y$ graph, as in Fig. 1. As can be seen from this figure, a yield advantage does not exist relative to cucumber monoculture when assessment is based on dollar value (with a distribution of only Grade 2 cucumbers).

Figure 2 shows values expected (by interpolation) for each croppingsystem if only various ratios of Grade 1 to Grade 2 cucumbers are obtained. At intermediate ratios (ca. $0.30<$ ratio $<0.68$ ), polyculture would give the highest return. Figure 2 implicitly assumes that the number of fruits remains constant, an assumption likely to be violated, but which nonetheless illustrates how grade-distribution is important in assessing the relative economic value of intercropping.

TABLE III

Dollar values extrapolated for various cropping-systems assuming different grades of cucumbers obtained (cf. O'Sullivan and Colwell, 1980). Entries in the table are in $\$$ American $/$ ha. Tomatoes set at $\$ 71.5 / \mathrm{MT}$

\begin{tabular}{|c|c|c|c|c|c|}
\hline \multirow{3}{*}{$\begin{array}{l}\text { Cucumber } \\
\text { grade a }^{\text {a }}\end{array}$} & \multicolumn{5}{|c|}{ Value $(\$ / \mathrm{ha})$} \\
\hline & \multicolumn{3}{|l|}{ Polyculture } & \multicolumn{2}{|c|}{ Monoculture } \\
\hline & Cucumber & Tomato & Total & Cucumber & Tomato \\
\hline 1 & 641 & 2179 & 2820 & 1340 & 3477 \\
\hline 2 & 2662 & 2179 & 4841 & 5565 & 3477 \\
\hline 3 & 2595 & 2179 & 4774 & 5424 & 3477 \\
\hline 4 & 1532 & 2179 & 3711 & 3203 & 3477 \\
\hline
\end{tabular}

a Cucumber grading-standards:

\begin{tabular}{lll} 
Grade & Diameter $(\mathrm{mm})$ & \$American/MT \\
\hline 1 & $<25$ & 329.33 \\
2 & $25-32$ & 237.78 \\
3 & $32-41$ & 133.25 \\
4 & $41-51$ & 56.87
\end{tabular}




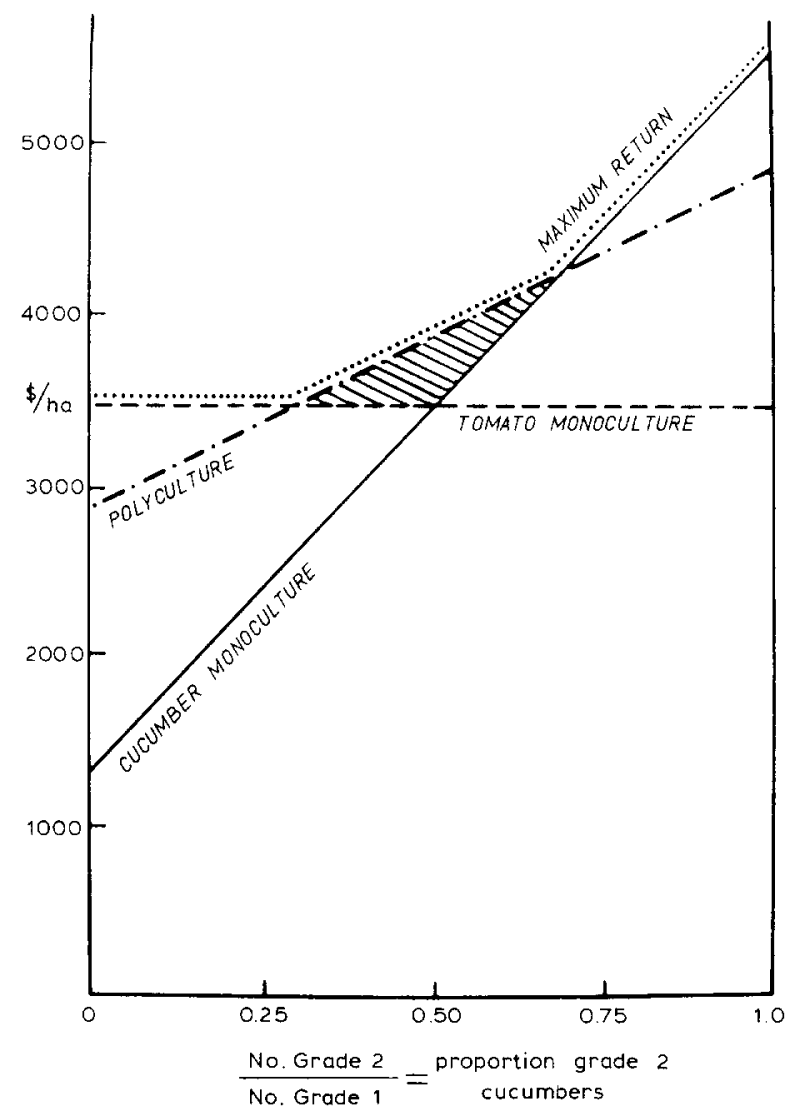

Fig. 2. Relationship between economic yield and grade distribution, assuming constant numbers of cucumbers of varying proportions of Grades 1 or 2 .

In terms of stability, there was no significant difference between monoculture and polyculture in the coefficients of variation among blocks, using the sums of the yields by weight of each crop. Both gave coefficients of variation of approximately $14 \%$. The analysis compensated for the greater area planted in monoculture due to the use of 2 monoculture plots per block, versus 1 polyculture plot. The yields of the polyculture plots were compared to randomly-paired sub-plots (within blocks) of the monocultures. Therefore, the total area, and any associated spatial heterogeneity, was equally sampled for monoculture and polyculture. The variation in the combined weight of tomatoes and cucumbers from the polyculture replicates, as well as that of the combined weights of the monocultures, were slightly lower than the variation calculated separately for each monoculture; tomatoes $(C V=15 \%)$ and cucumbers $(C V=18 \%)$.

\section{DISCUSSION}

The results suggest that intercropping technology could be developed for 
the tomato-cucumber combination. The relative yield totals averaged greater than 1 , an indication that more than 1 ha of monocultures would be required to equal the production of 1 ha of polyculture. More importantly, depending on prices, polycultures can provide a greater dollar value per ha than monoculture.

The advantages of polyculture are not contradicted by the observation that one monoculture can be the most profitable method per ha. As long as there is a sufficient market demand for the other crop to be grown at all, it may best be grown in polyculture, rather than by taking land away entirely from production of the more valuable crop. Diversification using monocultures of tomatoes and cucumbers has already been suggested in Ohio (Schurle and Erven, 1979).

Coefficients of variation here were small (cf. Kass, 1978; Rao and Willey, $1980 \mathrm{~b}$ ). It seems likely that differences in variation during a controlled single-factor experiment within a season will underestimate practical differences in regional or seasonal variation. It must be further noted, however, that spatial variation does not tend to correspond well to temporal variation in agriculture (Watson and Anderson, 1977). On the other hand, given equal coefficients of variation, some reduction in risk of disastrously poor returns must follow from the higher overall mean returns of the intercrop (Rao and Willey, 1980b).

Whatever the mechanism affecting price (e.g. market conditions, cucumber grade distribution), to the extent that the per ha dollar value of a tomato monoculture is equal to the per ha dollar value of a cucumber monoculture, the polyculture is more likely to show an advantage (see Figs. 1 and 2). For our data, if the ratio between tomato and cucumber monoculture "values" are between 0.91 and 1.17 , the polyculture will give a better return.

The results reported here need to be verified on other soils, in other years, and for other planting-patterns and densities. By holding the densities of each crop-type constant, we attempted to hold constant the effects of intraspecific competition. It is likely that better yields and improved stability will be obtainable with other densities and patterns. The densities used here represent only a first attempt, and some simple models suggest that more favorable densities can be found. Such experiments are currently being planned. The effect of cucumber grade-variation also suggests that studies of the ripening-process of cucumbers, in relation to intercropping, will be important to any complete economic analysis. Finally, input costs need to be considered (e.g. intercrops may be more expensive to plant but less expensive to weed).

In summary, the data presented here strongly suggest that intercropping of tomatoes and cucumbers might prove advantageous. At minimum, further work is clearly warranted. Different densities must be studied, along with investigations of the effect of intercropping on grades of both tomatoes and cucumbers. 


\section{ACKNOWLEDGEMENTS}

We wish to thank the staff of the Matthaei Botanical Gardens for use of land and facilities, land preparation, and much invaluable advice throughout the course of this study. Appreciation is also extended to the University of Michigan office of the Dean for Research for purchase of irrigation equipment. Katherine Yih and Michael Hansen read the manuscript and offered critical advice.

\section{REFERENCES}

ASA, 1976. Multiple Cropping. American Society of Agronomy Special Publ. 27, Madison, WI, viii $+378 \mathrm{pp}$.

Ells, J.E. and McSay, A.E., 1981. Yield comparisons of pickling cucumber cultivar trials for once-over harvesting. Hortic. Sci., 16: 187-189.

Fisher, N.M., 1979. Studies in mixed cropping. III. Seasonal results with maize-bean mixtures. Exp. Agric., 15: 49-58.

Kass, D.C.L., 1978. Polyculture cropping systems: review and analysis. Cornell Int. Agric. Bull. 32, 69 pp.

Norman, D.W., 1974. Rationalizing mixed cropping under indigenous conditions: the example of northern Nigeria. J. Devel. Stud., 11: 3-21.

O'Sullivan, J. and Colwell, H.T.M., 1980. Effect of harvest date on yield and grade distribution relationships for pickling cucumbers harvested once-over. J. Am. Soc. Hortic. Sci., 105: 408-412.

Rao, M.R. and Willey, R.W., 1980a. Preliminary studies of intercropping combinations based on pigeonpea or sorghum. Exp. Agric., 16: 29-39.

Rao, M.R. and Willey, R.W., 1980b. Evaluation of yield stability in intercropping studies on sorghum/pigeonpea. Exp. Agric., 16: 105-116.

Schurle, B.W. and Erven, B.L., 1979. The return-risk tradeoffs associated with processing tomato production in northwestern Ohio. Ohio Agric. Res. Dev. Center Bull. No. 111, $24 \mathrm{pp}$.

Trenbath, B.R., 1974. Biomass productivity of mixtures. Adv. Agron., 26: 177-210.

Watson, W.D. and Anderson, J.R., 1977. Spatial v. time-series data for assessing response risk. Rev. Mark. Agric. Econ., 45: 80-84.

Willey, R.W., 1979. Intercropping - Its importance and research needs. Parts I and II. Field Crop Abstr., 32: 1-10, 73-85. 